\title{
Preferential flow modelling in the vadose zone using MACRO 5.0: cape flats sands and Mpumalanga clays case studies (South Africa)
}

\author{
N. Z. Jovanovic ${ }^{1}$, K. A. Majola ${ }^{2}$, M. Ginster ${ }^{3}$ \& S. Adams ${ }^{4}$ \\ ${ }^{I}$ CSIR, Natural Resources and Environment, Stellenbosch, South Africa \\ ${ }^{2}$ Council of Geoscience, Pretoria, South Africa \\ ${ }^{3}$ SASOL, Safety, Health and Environment Centre, \\ Johannesburg, South Africa \\ ${ }^{4}$ Water Research Commission, Pretoria, South Africa
}

\begin{abstract}
Understanding fluid flow and solute transport within the vadose (unsaturated) zone is an essential prerequisite for protection of groundwater from contaminant sources occurring overland. Preferential flow paths in the vadose zone pose a significant problem because they are potential avenues for rapid transport of chemicals from contamination sources to the water table. The objectives of this study were i) to test the adequacy of a model, namely MACRO 5.0, in simulating bimodal water flow and generic contaminant transport in the vadose zone, and ii) to run a sensitivity analysis with MACRO 5.0 in order to determine which input parameters are the most relevant in describing the effects of preferential water flow, solute transport and exchange between macropores and matrix. Two case studies were investigated, the first at a landfill site overlying sandy unconfined aquifer (Coastal Park, Cape Town), and the second at an industrial site overlying cracking clayey soil and fractured rocks (Secunda, Mpumalanga Province). For the Coastal Park site, simulations of soil water content and leaching of a mobile tracer were compared to monitored soil water contents and chloride concentrations in groundwater. For the Secunda site, simulations of soil water content and concentrations of boron and fluoride originating from effluent irrigation were compared to soil profile measurements. In both cases, the MACRO 5.0 model predictions agreed well with measurements, appropriate input calibration data were used. The sensitivity analysis indicated that soil water properties related to preferential flow (hydraulic conductivity at the boundary between macropores and matrix, soil water content and tension, and diffusion pathlength) have influence on simulation results. Similarly, the solute balance is mostly influenced by degradation rate coefficients (both in solid and liquid phases), sorption distribution coefficients and solute concentrations.
\end{abstract}

Keywords: cape flats, MACRO 5.0, preferential flow, Secunda, sensitivity analysis, vadose zone. 


\section{Introduction}

The Government of South Africa recognizes the importance of protecting groundwater resources from pollution. As a result, the Water Research Commission (WRC, Pretoria, South Africa) initiated a cycle of research in order to establish a framework for groundwater protection [1], to provide baseline data on the types of contaminants that pose a significant threat to groundwater, the environment and health in urban catchments [2], and to develop improved approaches, tools and protocols for site-specific aquifer vulnerability assessment in South African urban catchments, in particular making use of available information on soils [3]. As a result, novel approaches and tools were developed to assist decision-makers on framing various activities.

An outcome of this research was that aquifer vulnerability assessment is not a straightforward exercise as there is often a host of contributing physico-chemical factors [3]. Existing techniques seldom consider soil properties in any level of detail and are generally based on soil thickness and physical properties such as grain size. Yet the soil is often the 'first line of defense' against the migration of contaminants to groundwater from overlying land-based activities, and soil chemical and physical properties can play a major role in the protection or impact of aquifers [4]. One of the most difficult physical factors to account for in groundwater contamination studies is preferential flow through the vadose zone. Preferential flow paths may occur as short-circuiting, fingering and funneling [5], and they are a major concern for estimating accurately the vulnerability of aquifers to contamination. They also affect other processes related to leaching and groundwater contamination. For example, it is known that flow occurring through preferential paths is fast (short travel times), resulting in lower contaminant attenuation through, for example, sorption or degradation.

Preferential flow in soils is generally described with dual-porosity/dualpermeability models by assuming that the medium consists of two pore regions that exchange fluxes, the one associated with macropores, and the other with micropores inside soil aggregates. This principle is used in MACRO, a onedimensional model for transient fluxes of water, heat and solute in the vadose zone [6]. The general objective of this study was to use the MACRO 5.0 model in order to determine the extent of preferential flow effects on groundwater contamination at two South African sites characterized by different soil properties. The specific objectives were i) to calibrate and test MACRO 5.0 for two case study sites, namely Cape Flats sands and Mpumalanga clays, and ii) to perform a sensitivity analysis to determine which input model parameters are the most relevant in describing the effects of preferential flow on water and solute transport. 


\section{Material and methods}

\subsection{Brief description of MACRO 5.0}

MACRO is a deterministic, one-dimensional, transient model for water, heat and solute transport in layered soils [6]. It simulates micropore and macropore flow by dividing soil porosity into two domains, each characterized by a degree of saturation, conductivity, flux and solute concentration. Unsaturated water flow in micropores is calculated with Richards' equation, whilst flow is driven by gravity in macropores using a capacitance approach. Solute transport in micropores is simulated with the convection-dispersion equation, whilst it is driven by water fluxes solely in macropores. Mass exchange of water and solutes between macropores and micropores is simulated through approximate firstorder rate equations. The field water balance processes include: i) precipitation and evapotranspiration (input data); ii) vertical water fluxes; iii) canopy interception; iv) root water uptake calculated with an empirical sink term with water preferentially extracted from macropores; v) deep seepage, formation of perched water tables and horizontal fluxes to tile drains can also be simulated. The solute transport and transformation processes include: i) vertical fluxes; ii) canopy wash-off; iii) instantaneous/kinetic sorption using Freundlich isotherms in micropores and macropores; iv) first-order degradation controlled by soil moisture and temperature in solid, liquid, micropore and macropore pools; v) plant uptake. The types of solutes are non-reactive tracers such as bromide and chloride, tritium and pesticides. Soil temperature is simulated with the heat conduction equation.

\subsection{Study sites}

Two study sites were selected to apply the MACRO 5.0 model:

- Goedehoop irrigation site near Secunda in the Mpumalanga Province

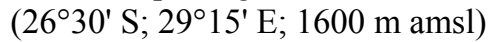

- Coastal Park waste disposal site near Cape Town $\left(34^{\circ} 05^{\prime} \mathrm{S} ; 18^{\circ} 31^{\prime} \mathrm{E} ; 10 \mathrm{~m}\right.$ amsl)

SASOL operates a large petrochemical facility at Secunda. Some surplus ammonia rich process effluent containing elevated concentrations of fluoride and boron have been disposed of by permitted irrigation, exploiting evaporation to get rid of the excess water. This was a method approved by the South African Department of Water Affairs and Forestry. Effluent has been irrigated onto pasture land from 1991 to 2000 at the Goedehoop site (fig. 1). Soil properties and groundwater quality were monitored during this period. The climate is subhumid, with mean annual rainfall of $700 \mathrm{~mm}$ predominantly in summer, and Class-A pan evaporation amounts at $1700 \mathrm{~mm} \mathrm{a}^{-1}$. Weekly irrigations were scheduled to refill the soil water deficit. The area is drained by the Klipspruit river in the catchment of the Waterval river. The site is underlain by an unconfined to semi-confined weathered/fractured aquifer in Karoo sediments. Two major soil types occur: a duplex Swartland soil form [7] (sandy A horizon over a clay-rich B-horizon) or Luvisol [8] upslope; and a Rensburg soil form [7] 


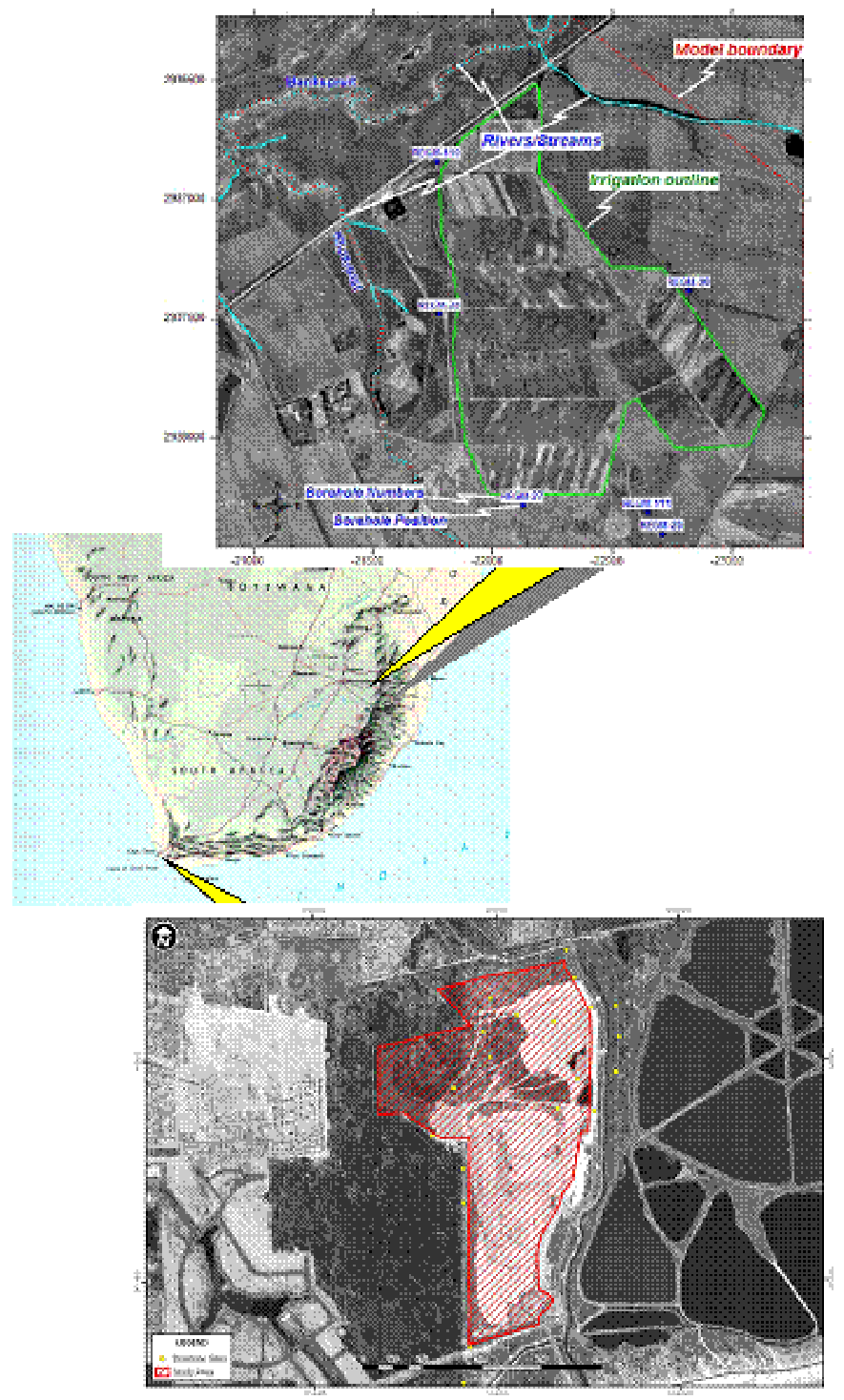

Figure 1: Location and layout of the Goedehoop irrigation site near Secunda (top image) and the Coastal Park waste disposal site near Cape Town (bottom image).

(black smectitic clay) or Vertisol [8] in the low-lying areas. The geology and the duplex soil association are both representative of large parts of the South African interior. The swelling and shrinking of the clays inevitably lead to the formation of cracks. It is thus safe to assume that preferential flow occurs to at least some depth. The groundwater depths ranged from 3 to $16 \mathrm{~m}$. Historic data of irrigation 
amounts and quality, as well as monitored data of soil and groundwater were used as inputs in the MACRO model. Simulated soil water contents and soil profile concentrations of $\mathrm{B}$ and $\mathrm{F}$ were compared to measured data in order to calibrate and test the model at this site.

The Coastal Park waste disposal site serves the City of Cape Town and is located on the primary unconfined Cape Flats Aquifer (CFA) (fig. 1). The climate is Mediterranean with hot dry summers and cool wet winters. Mean annual precipitation is approximately $600 \mathrm{~mm}$, with $80 \%$ of the annual rain falling in the winter season between March and September. The CFA comprises a 20 to $30 \mathrm{~m}$ thick Quaternary sand succession resulting in a Namib soil form [7] or Arenosol [8], whilst the lower part of the aquifer is bounded by a clay aquitard. The water table depth varies between 1 and $5 \mathrm{~m}$ depending on the season. Regional groundwater flow is to the south to False Bay. Major contaminants produced at the Coastal Park site are nutrients $(\mathrm{N}, \mathrm{P}, \mathrm{K})$, salinity, pathogenic micro-organisms, organic contaminants (fuels, solvents) and trace metals. Geochemical processes, low hydraulic gradients and rapid and abundant recharge of the aquifer may reduce its vulnerability to contamination to some degree or at least enhance its capacity to recover from contamination. The impact of the Coastal Park waste disposal site on the aquifer has been extensively studied $[9,10]$. Numerous groundwater monitoring wells and mini-piezometers have been installed (fig. 1), including lines of wells to monitor down-gradient groundwater quality at various distances from the waste site. Data from these studies were used as inputs in the MACRO model. Simulated soil water contents and concentrations of $\mathrm{Cl}$ in groundwater were compared to measured data in order to calibrate and test the model at this site for the period from 1999 to 2004. A constant source of $\mathrm{Cl}$ at the surface was assumed $\left(1400 \mathrm{mg} \mathrm{L}^{-1}\right.$ in infiltrating water) and the driver for leaching was rainfall.

Table 1: $\quad$ Soil properties used as inputs in the MACRO 5.0 model for the two case study sites.

\begin{tabular}{|c|c|c|c|c|c|}
\hline Property & \multicolumn{3}{|c|}{ Mpumalanga } & \multicolumn{2}{c|}{ Cape Flats } \\
\hline Horizon & Ap & B & C & Ap & B \\
\hline $\begin{array}{c}\text { Thickness } \\
\text { (cm) }\end{array}$ & 200 & 200 & 400 & 50 & 250 \\
\hline $\begin{array}{c}\text { Structural } \\
\text { shape }\end{array}$ & Granular & Granular & Granular & Granular & Granular \\
\hline Texture & $\begin{array}{c}\text { Sandy } \\
\text { clay loam }\end{array}$ & Clay & Clay & Sand & Sand \\
\hline Clay (\%) & 26 & 42 & 46 & 0 & 1 \\
\hline Silt (\%) & 22 & 22 & 22 & 0 & 5 \\
\hline Sand (\%) & 52 & 36 & 32 & 100 & 94 \\
\hline $\begin{array}{c}\text { Bulk density } \\
\text { (g cm }\end{array}$ & 1.2 & 1.4 & 1.4 & 1.2 & 1.5 \\
\hline $\begin{array}{c}\text { Organic C } \\
(\%)\end{array}$ & 1.3 & 1.1 & 0.5 & 2.0 & 1.0 \\
\hline
\end{tabular}


Climatic data were obtained from the South African Weather Services for both sites and daily reference evapotranspiration was calculated with the Penman-Monteith equation [11]. Sixty numerical layers were assigned to the soil profile for simulations at both sites, whilst the bottom boundary condition was the ground water table. Table 1 summarizes the soil properties used as input in MACRO for the two sites. All details of input data used can be found in [12].

\subsection{Sensitivity analyses}

A sensitivity analysis was carried out in order to identify the model's input parameters that cause most changes in output parameters related to preferential flow. This was done by changing values of input parameters and recording changes of volumetric soil water content and soil profile concentrations of contaminants at different depths for snapshots in time, as well as percolation and leaching over time.

Contaminant transport in the vadose zone depends on both the properties of the medium and the properties of the pollutant. Values were varied for a large number of input parameters and simulations run. These input variables were related to soil textural properties (clay, silt, sand percentages, bulk density, slope of shrinkage characteristic), soil water retention properties (saturated and residual volumetric soil water content, saturated soil hydraulic conductivity, van Genuchten's $\alpha$ and $n$ values of the soil water retention function), flow in the micro- and macropore domains (exponent in the power function relating macropore hydraulic conductivity to macroporosity, effective diffusion pathlength, excluded volumetric water content), flux exchange between the two flow domains (volumetric soil water content, soil water tension, hydraulic conductivity at the boundary between micropores and macropores) and solute properties (sorption distribution coefficient, degradation rate coefficients in the micro- and macropores in liquid and solid phases).

\section{MACRO 5.0 simulations}

\subsection{Model calibration}

The first step in model calibration was to ensure an acceptable simulation of soil water contents by comparison with available field measurements for both study sites. This was done by refining the input data until a good visual fit between measurements and simulations was achieved. The results of these simulations can be found in [12]. Concentrations of salts in the soil profiles were then simulated and the outputs compared to available measurements.

Fig. 2 shows a comparison between measured and simulated concentrations of $\mathrm{B}$ and $\mathrm{F}$ in the soil profile at Goedehoop (Secunda). The measurements were made at the beginning (1991) and end (2002) of the irrigation period. From historical data, it is evident that there was already in the early 1990s a build-up of solutes in the top soil, in particular B. At the end of the irrigation period, both concentrations of hot water extractable B and water soluble $\mathrm{F}$ were relatively 

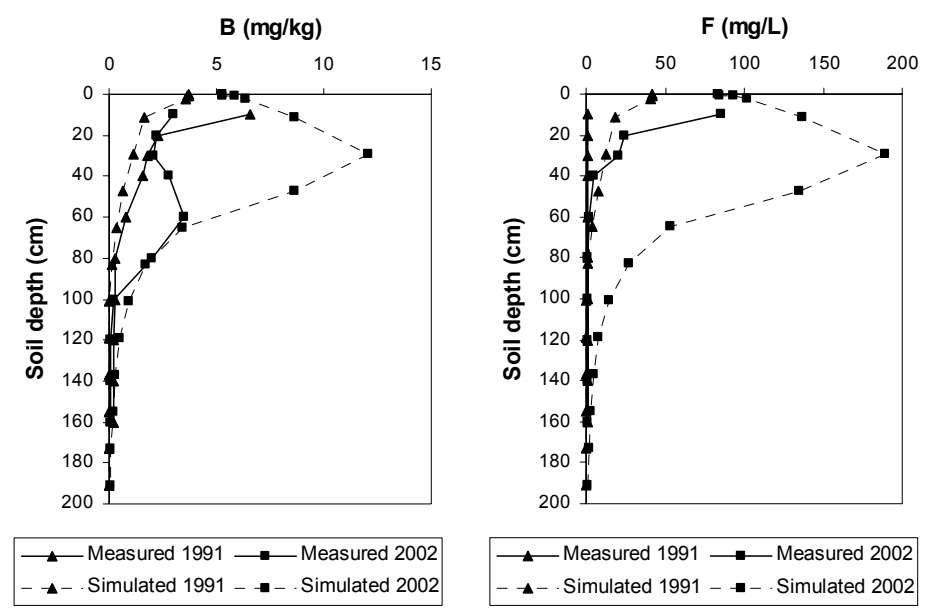

Figure 2: Measured and simulated concentrations of $\mathrm{B}$ (hot water extractable) and F (saturated paste extractable) in the soil profile at the Goedehoop irrigation site (Secunda).

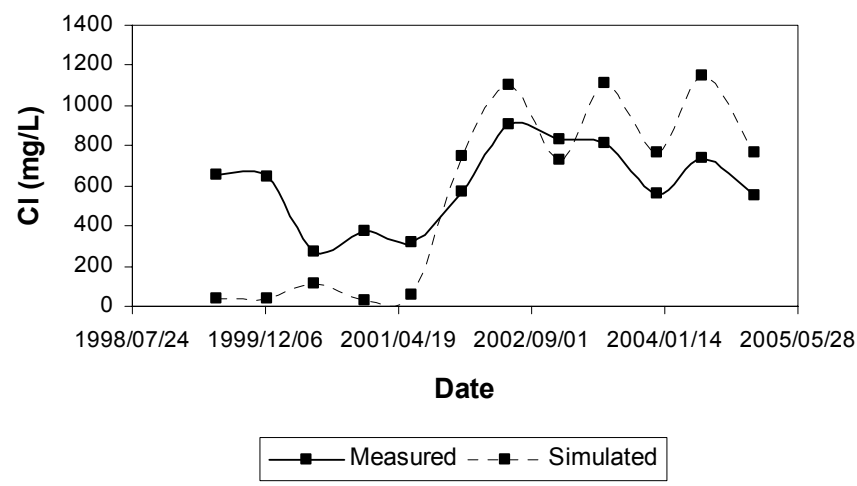

Figure 3: $\quad$ Measured and simulated concentrations of $\mathrm{Cl}$ in groundwater at the Coastal Park waste disposal site (Cape Town).

high down to $100 \mathrm{~cm}$ soil depth, indicating movement of the center of mass of solutes downwards through leaching. The concentration of $\mathrm{F}$ was higher compared to $\mathrm{B}$ due to the higher concentration in irrigation water applied and the strong sorption properties of F. The simulated salt profiles followed measured trends and they were in the same order of magnitude as measured data for both ionic species (fig. 2).

For the Coastal Park landfill waste disposal site, simulated concentrations of $\mathrm{Cl}$ in groundwater were compared to measurements [10] for the period from 1999 to 2004 . With exception of the initial period, the simulated concentrations 
of $\mathrm{Cl}$ followed the trends of measured data very well (fig. 3). Besides some discrepancies, the good agreement between measured and simulated data gave confidence in the predictive capabilities of the model for both study sites.

\subsection{Sensitivity analysis}

The sensitivity analyses allowed to indicate which input parameters are the most important to measure or estimate accurately, and what are the expected differences at two sites with different soil properties, climate and management conditions, in particular in terms of preferential flow and groundwater contamination. The main findings of the sensitivity analyses can be summarized as follows:

- Climate plays a role in water and solute transport. In the presence of cracking soils, macropore flow is more frequent in wet climates; it does not only depend on total rainfall, but perhaps more importantly on rainfall distribution and intensity.

- The unsaturated zone of the Coastal Park site was less affected by preferential flow compared to the Goedehoop site, primarily due to soil properties (shrinkage characteristics). This was evident from the soil profile simulations of water content and solute concentration, where larger fluctuations occurred at the Goedehoop site. This was attributed to the existence of preferential flow paths caused by soil cracking at this site, whilst flow occurs mainly through the matrix in the unconsolidated porous sands at Coastal Park.

- Although the unsaturated zone is thicker at Goedehoop compared to Coastal Park (deeper groundwater table), more percolation and leaching was calculated at Goedehoop for the given climatic data with no additional source of water through irrigation. This was attributed to higher total rainfall at Goedehoop compared to Coastal Park, as well as preferential flow paths. In addition, rainfall intensity and distribution played a role (summer thundershowers of high intensity at Goedehoop compared to winter rainfall of low intensity at Coastal Park).

- Soil textural properties (clay, silt, sand percentages, bulk density, slope of shrinkage characteristic) play an important role in bimodal flow and they affect percolation and leaching.

- $\quad$ Soil properties like structure and structural shape did not have a large effect on macropore flow.

- Concerning soil water retention properties, changes in saturated soil hydraulic conductivity had an important effect on percolation and leaching, whilst variations in saturated and residual volumetric soil water content, van Genuchten's $\alpha$ and $\mathrm{n}$ values of the soil water retention function did not.

- Concerning parameters related to the flux exchange between the micro- and macropore domains, the boundary hydraulic conductivity and effective diffusion pathlength had a large effect on simulation results of the water balance. 
- The solute balance was mostly influenced by solute concentrations at source and solute properties, in particular sorption and degradation rate coefficients for degradable compounds.

- Higher solute concentrations generally occurred in micropores compared to macropores, irrespective of any other variable.

\section{Conclusions}

Aquifer vulnerability assessment is a complex exercise due to the number of hydrogeological and specific contaminant factors involved and their interactions. The effects of one of the most difficult factors to quantify, namely preferential flow, were evaluated using the MACRO 5.0 model in two different South African environments. MACRO 5.0 was found to be suitable for predictions of water and solute transport in the unsaturated zone of both sandy and heavy cracking clay soils. Sensitivity analyses indicated which input parameters related to preferential flow are the most important to measure or estimate accurately at the two case study sites. Amongst others, these were boundary hydraulic conductivity and effective diffusion pathlength for the water balance, and solute concentrations, sorption and degradation rate coefficients for the solute balance. The availability and adequacy of data or lack thereof, is an important issue because many of the model's inputs related to preferential flow are not easy to obtain and measure, and they require extensive field and laboratory experimentation.

\section{Acknowledgement}

The authors wish to acknowledge the financial support of the Water Research Commission (Pretoria, South Africa).

\section{References}

[1] Sililo, O.T.N., Saayman, I.C. \& Fey, M.V., Groundwater Vulnerability to Pollution in Urban Catchments. Water Research Commission report No. 1008/1/01: Pretoria, South Africa, 2001.

[2] Usher, B.H., Pretorius, J.A., Dennis, I., Jovanovic, N., Clarke, S., Cave, L., Titus, R. \& Xu, Y., Identification and Prioritisation of Groundwater Contaminants and Sources in South Africa's Urban Catchments. Water Research Commission report No. 1326./1/04: Pretoria, South Africa, 2004.

[3] Saayman, I.C., Beekman, H.E., Adams, S., Campbell, R.B., Conrad, J., Fey, M.V., Jovanovic, N., Thomas, A. \& Usher, B.H., Assessment of Aquifer Vulnerability in South Africa. Water Research Commission report No. K5/1432: Pretoria, South Africa, 2007.

[4] Sililo, O.T.N., Conrad, J., Murphy, K.O.H., Tredoux, G., Eigenhuis, B., Ferguson, M.C.D. \& Moolman, J.H. Investigation of the Contaminant Attenuation Characteristics of the Soil Aquifer System with Special 
Emphasis on the Vadose Zone. Water Research Commission report No. 572/1/99: Pretoria, South Africa, 1999.

[5] Fetter, C.W., Contaminant Hydrogeology. 2nd edition. Prentice Hall: Upper Saddle River, New Jersey, 1999.

[6] Larsbo, M. \& Jarvis, N., MACRO 5.0 A Model of Water Flow and Solute Transport in Macroporous Soil. Technical Description, Emergo 2003: 6: Department of Soil Science, Swedish University of Agricultural Science, Uppsala, Sweden, 2003.

[7] Soil Classification Working Group, Soil Classification. A Taxonomic System for South Africa, Dept. of Agricultural Development: Pretoria, South Africa, 1991.

[8] FAO, World Reference Base for Soil Resources, Food and Agricultural Organization of the United Nations: Rome, Italy, 1998.

[9] Allen, R.G., Pereira, L.S., Raes, D. \& Smith, M., Crop Evaporation. Guidelines for Computing Crop Water Requirements, FAO Irrigation and Drainage Paper No. 56: FAO, Rome, Italy, 1998.

[10] Novella, P.H., Ballard, R.H., Stow, J.G., Ross, W.R., Blight, G.E. \& K. Vorster, Practical Application of Special Waste Co-disposal with Municipal Refuse at the Coastal Park Lanfill Bioreactor. Volume 1. Water Research Commission report No. 606/1/99: Pretoria, South Africa, 1999.

[11] Ball, J.M. \& Novella, P.H., Coastal Park Landfill: Leachate Plume Migration and Attenuation. City of Cape Town Monitoring Report: City of Cape Town, South Africa, 2003.

[12] Majola, K.A., Preferential Flow Modelling in the Vadose Zone Using MACRO 5.0 - Cape Flats Porous Sands and Secunda Clays Case Studies. MSc thesis: University of the Western Cape, South Africa, 2008. 